\title{
Topical treatments for diabetic neuropathic pain (Review)
}

\author{
XI-DING YANG ${ }^{1,2}$, PING-FEI FANG ${ }^{1,2}$, DA-XIONG XIANG ${ }^{1,3}$ and YONG-YU YANG Y,3 $^{1,3}$ \\ ${ }^{1}$ Department of Pharmacy; ${ }^{2}$ Phase I Clinical Trial Center; \\ ${ }^{3}$ Hunan Provincial Engineering Research Center of Translational Medical and Innovative Drug, \\ The Second Xiangya Hospital of Central South University, Changsha, Hunan 410011, P.R. China
}

Received June 4, 2018; Accepted November 22, 2018

DOI: $10.3892 /$ etm.2019.7173

\begin{abstract}
Diabetic neuropathic pain (DNP) has a huge impact on quality of life and can be difficult to treat. Oral treatment is the most frequently used method for DNP, but its use is often limited by systemic side effects. Topical use of drugs as an alternative option for DNP treatment is currently gaining interest. In the present review, a summary is provided of the available agents for topical use in patients with DNP, including lidocaine plasters or patches, capsaicin cream, gel or patches, amitriptyline cream, clonidine gel, ketamine cream, extracts from medicinal plants including nutmeg extracts and Citrullus colocynthis extract oil, and certain compounded topical analgesics. Furthermore, the potential efficacy of these treatments is addressed according to the available clinical research literature. It has been indicated that these topical drugs have the potential to be valuable additional options for the management of DNP, with adequate safety and continuous long-term treatment efficacy. Compounded topical agents are also effective and safe for patients with DNP and could be another area worthy of further investigation based on the strategy of using low-dose, complementary therapies for DNP. The findings indicate that developing topical drugs acting on different targets in the process of DNP is a valuable area of future research.
\end{abstract}

\section{Contents}

1. Introduction

2. Pathogenesis of DNP

3. Topical pharmacological treatment of DNP

4. Conclusion and perspectives

Correspondence to: Dr Yong-Yu Yang, Department of Pharmacy, The Second Xiangya Hospital of Central South University, 139 Renminzhong Road, Changsha, Hunan 410011, P.R. China E-mail: yongyuyang@csu.edu.cn

Key words: topical treatments, diabetes, diabetic neuropathy, diabetic neuropathic pain

\section{Introduction}

According to the International Diabetes Federation, there are 425 million adults with diabetes worldwide (1). Diabetic neuropathy is the most common complication of diabetes mellitus, becoming symptomatic after 14.5 years of chronic prolonged high blood glucose in type 1 diabetes, and after only 8.1 years in type 2 diabetes (2). A population-based study indicated that up to $50 \%$ of patients with either type 1 or type 2 diabetes develop diabetic neuropathy (3), and $15-30 \%$ of those manifestations are painful (4). Diabetic neuropathic pain (DNP) is among the most common, expensive and disabling complications of diabetes, affecting approximately $30 \%$ of patients with diabetes who are hospitalized and $25 \%$ of those in the community $(5,6)$.

DNP is characterized by sensations of numbness, burning pain and prickling or stinging around the hands and feet, and the pain is more severe at night (7). The more severe occurrences of DNP can be intractable $(8,9)$. Neuropathic pain can be constant and accompanied by cutaneous allodynia, which significantly influences quality of life (QOL) and prevents patients from performing their daily activities and roles of employment. The pain may also be associated with depression and may be a reason for withdrawal from recreational and social life $(7,10,11)$. Thus, treating this debilitating condition appropriately is important, particularly because of the impact on QOL and the associated depression and anxiety (12).

The management of DNP is challenging and can require a multi-modal approach involving early recognition, glycemic control and psychological therapy, as well as therapies for symptomatic pain relief (13-15). At present, the pharmacological treatments for DNP include oral and topical therapies (16). Oral agents, such as amitriptyline, duloxetine, pregabalin and gabapentin, are recommended as first-line drug treatments (17). However, oral therapy requires multiple medications taken at varying times of the day and is often associated with a significantly elevated risk of systemic side effects, which may be severe (18). Some patients do not tolerate these drugs and some find them ineffective, which may cause a significant drop in patient compliance. With the potential to provide the same level of analgesic efficacy provided by oral analgesics, but relatively fewer systemic adverse events and drug-drug interactions $(19,20)$, topical use of drugs as another treatment option for DNP is currently gaining interest $(16,21)$. A variety of agents are used in the topical treatments of DNP, including 
lidocaine, capsaicin, amitriptyline, clonidine, nutmeg extracts, Citrullus colocynthis extract oil and even a combination of various compounds, and so far offer promising results (22-28). Given the trend towards using topical medications to treat DNP, the present review provides an overview of the current knowledge regarding the physiopathology of DNP and the existing topical pharmacological treatments. A recent review, focusing on topical treatment for localized neuropathic pain, including post-herpetic neuralgia (PHN), complex regional pain syndrome, diabetic peripheral neuropathy and human immunodeficiency virus distal sensory polyneuropathy, has been published (29). In the current review, an overview is provided of the current understanding of the pathogenesis of DNP and the mechanism of drug action. Furthermore, the clinical data on available agents for topical use in patients with DNP is summarized, their potential efficacy addressed, and the potential for use of compounded topical agents in the future is highlighted.

\section{Pathogenesis of DNP}

The exact pathogenic mechanisms involved in the generation of DNP are not fully established (8). A variety of potential factors have been postulated to elicit the pain associated with diabetic neuropathy, including hyperglycemia, advanced glycation end-products (AGEs)/AGE receptor (RAGE) activity, oxidative stress, neuroinflammation and endoneural hypoxia (30,31). A schematic summarizing the potential mechanisms underlying the pathogenesis of DNP is presented in Fig. 1.

There is a consensus that hyperglycemia serves a crucial role in the development of DNP (2,32-36). Studies in non-diabetic individuals and in animals have demonstrated that hyperglycemia can cause a decrease in pain thresholds $(34,35)$. Hyperglycemia is correlated with the progression of neuropathy pain; approximately $50 \%$ of patients who have had diabetes for more than 25 years will develop neuropathy and the majority of symptomatic patients will complain of pain $(2,36)$.

Other factors besides hyperglycemia may result in the generation of DNP (37). An increase in AGE production and a decrease in the regeneration of glutathione may be caused by hyperglycemia $(38,39)$. Depletion of glutathione could be the primary cause of oxidative stress and related to the accumulation of toxic species (40). In addition, when the disposal of intracellular glucose is impaired, alternate pathways are activated, which may also lead to oxidative stress and nerve injury (41-43). Hyperglycemia serves a key role in oxidative stress in diabetic nerves (41). Nerve hypoxia may be evoked by hyperglycemia, particularly in sensory nerves, altering their function and electrical stability (44). AGEs, oxidative stress and hypoxia thereby cause the production of inflammatory cytokines and growth factors, which in turn cause neuroinflammation and nerve injury (45-47). Neuropathic pain has been associated with neurological damage to the function of sensory fibers, including fast-conducting myelin-

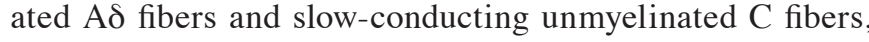
which conduct nerve impulses, and changes in voltage-gated ion channel distribution and expression $(48,49)$. In addition, the upregulation of transient receptor potential vanilloid 1 (TRPV1) expression has been identified to be associated with neuropathic pain (50). Hyperglycemia, AGEs, hypoxia and oxidative stress-mediated damage in neurons and glial cells, as well as the subsequent activation of proinflammatory cascades and crosstalk between these disease processes, may ultimately result in abnormal ectopic discharges and abnormal synaptic neurotransmitter release, including of serotonin and norepinephrine (8), and thereby trigger development of neuropathic pain (51).

\section{Topical pharmacological treatment of DNP}

The analgesic effect and safety of various topical agents including lidocaine plasters and patches, capsaicin cream, capsaicin gel, capsaicin patches, amitriptyline cream, clonidine gel, ketamine cream, extracts from medicinal plants including nutmeg extracts and Citrullus colocynthis extract oil, and some compounded topical analgesics, have been assessed in patients affected by DNP. Topical agents evaluated in clinical trials are discussed in detail herein and their targets of action are presented in Fig. 2.

Topical lidocaine. Lidocaine, a blocker of voltage-gated sodium channels (particularly Nav 1.7 and 1.8), can stabilize the neuronal membrane potential on abnormally excitable $\mathrm{A} \delta$ and $\mathrm{C}$ fibers, resulting in a reduction of ectopic discharges $(52,53)$. This raises the peripheral ectopic discharge threshold and reduces the pain transduction. Topical lidocaine has been demonstrated to be effective in the treatment of neuropathic pain conditions, including DNP (54-57). A network meta-analysis compared 5\% lidocaine-medicated plaster for the relief of DPN with other relevant drugs, including amitriptyline (30, 75 and $125 \mathrm{mg} /$ day), pregabalin (300 and $600 \mathrm{mg} /$ day), capsaicin $(0.075 \%$ cream, four times a day), gabapentin ( $\leq 900$ and $1,200 \mathrm{mg} /$ day) and placebo. It was indicated that all interventions were effective in comparisons with a placebo. Notably, lidocaine medicated plasters were comparable to all of the other interventions (58).

Here, five reports that assessed the effectiveness of topical lidocaine for DNP have been reviewed (Table I). A 4-week, randomized, open-label, multicenter, non-inferiority study, which compared lidocaine plaster with pregabalin in patients with DNP, was reported as an interim analysis (59) and published in full $(52,60)$. The interim analysis revealed that patients administered with $5 \%$ lidocaine plasters experienced similar analgesic efficacy, fewer drug-related adverse events (DRAEs; 3.9 vs. 39.2\%) and substantially fewer discontinuations due to DRAEs (1.3 vs. 20.3\%) than pregabalin (59). In the full analysis the investigators also reported results for EuroQol-5D (EQ-5D) QOL evaluation. In line with the aforementioned results, $5 \%$ lidocaine-medicated plaster exerted comparable efficacy, greater improvements in the QOL based on EQ-5D, and fewer adverse events, DRAEs and related discontinuations compared with pregabalin (52). To our knowledge this was the only study that has assessed the lidocaine plaster as a monotherapy for DNP. An 8-week combination phase of this study also demonstrated additional decreases in recalled average pain intensity scores over the previous 3 days (numeric rating scale-3 scores) (60). Another open-label study on patients with DPN who experienced pain following a stable analgesic drug regimen and dosages for at least a week, and 


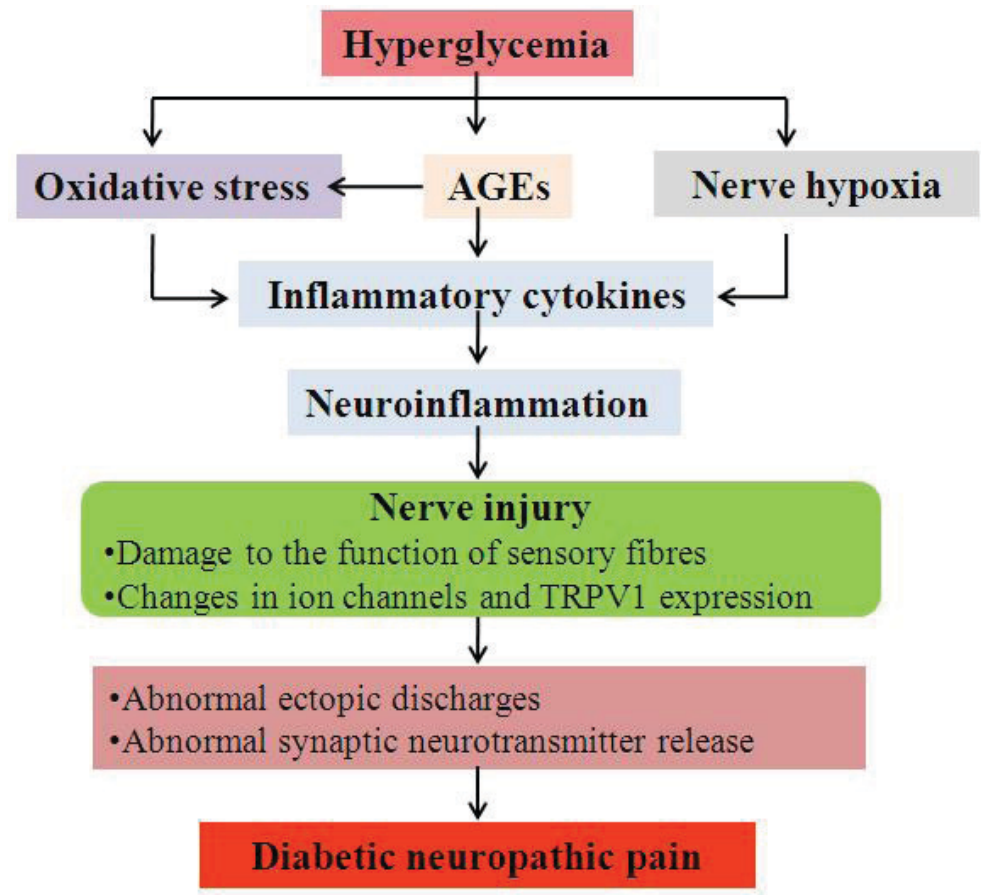

Figure 1. A summary of the pathogenesis of DNP. DNP, diabetic neuropathic pain; AGEs, advanced glycation end-products; TRPV1, transient receptor potential vanilloid 1 .

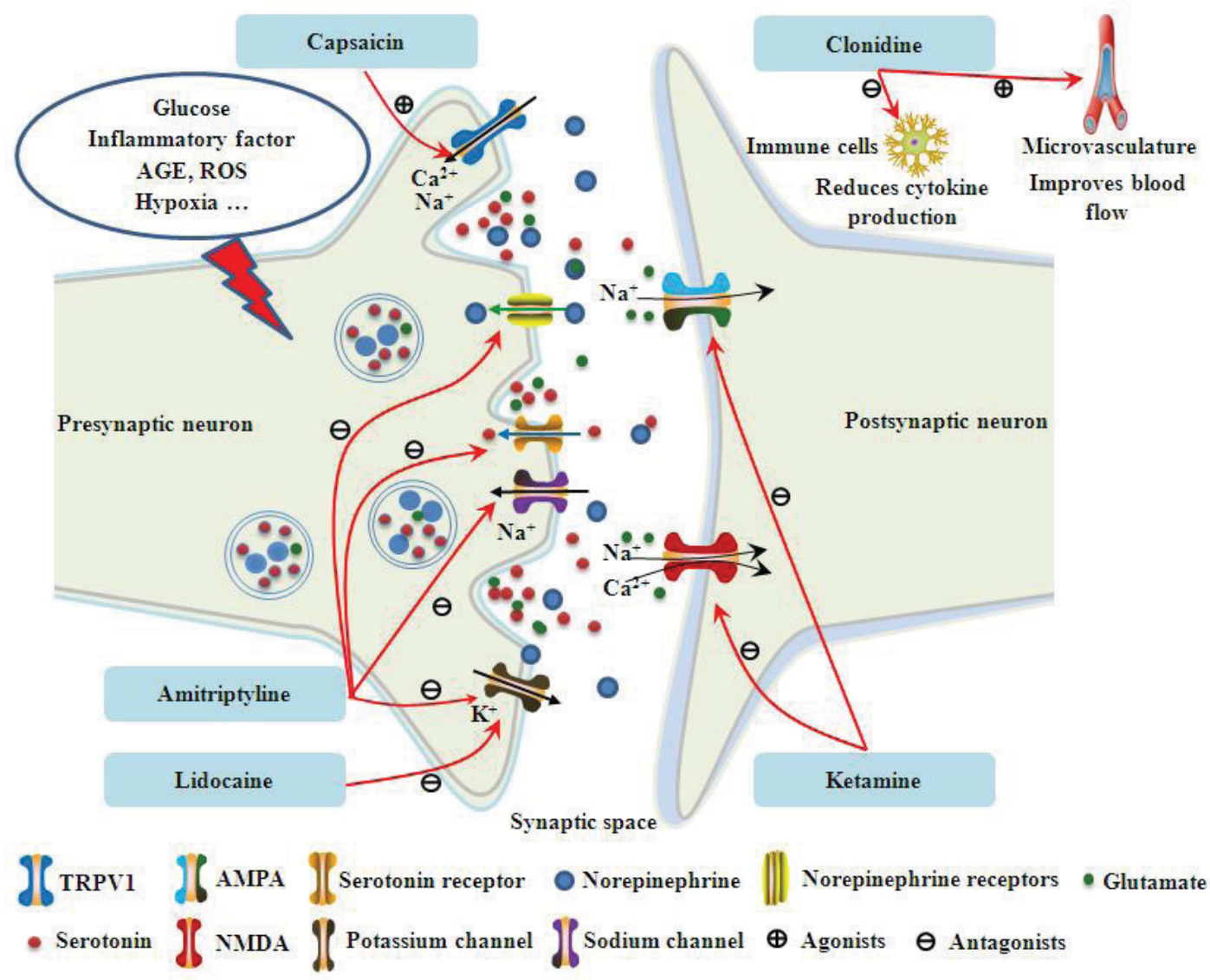

Figure 2. Therapeutic targets of topical agents for DNP. AGEs, advanced glycation end-products; ROS, reactive oxygen species; TRPV1, transient receptor potential vanilloid 1; AMPA, a-amino-3-hydroxy-5-methylisoxazole-4-proprionic acid; NMDA, N-methyl-D-aspartate; DNP, diabetic neuropathic pain.

presented with an average daily pain diary rating of $\geq 4$ on the brief pain inventory, exhibited significant improvements in pain and QOL outcome measures during a 3-week 5\% lidocaine patch treatment period. These benefits were maintained during 


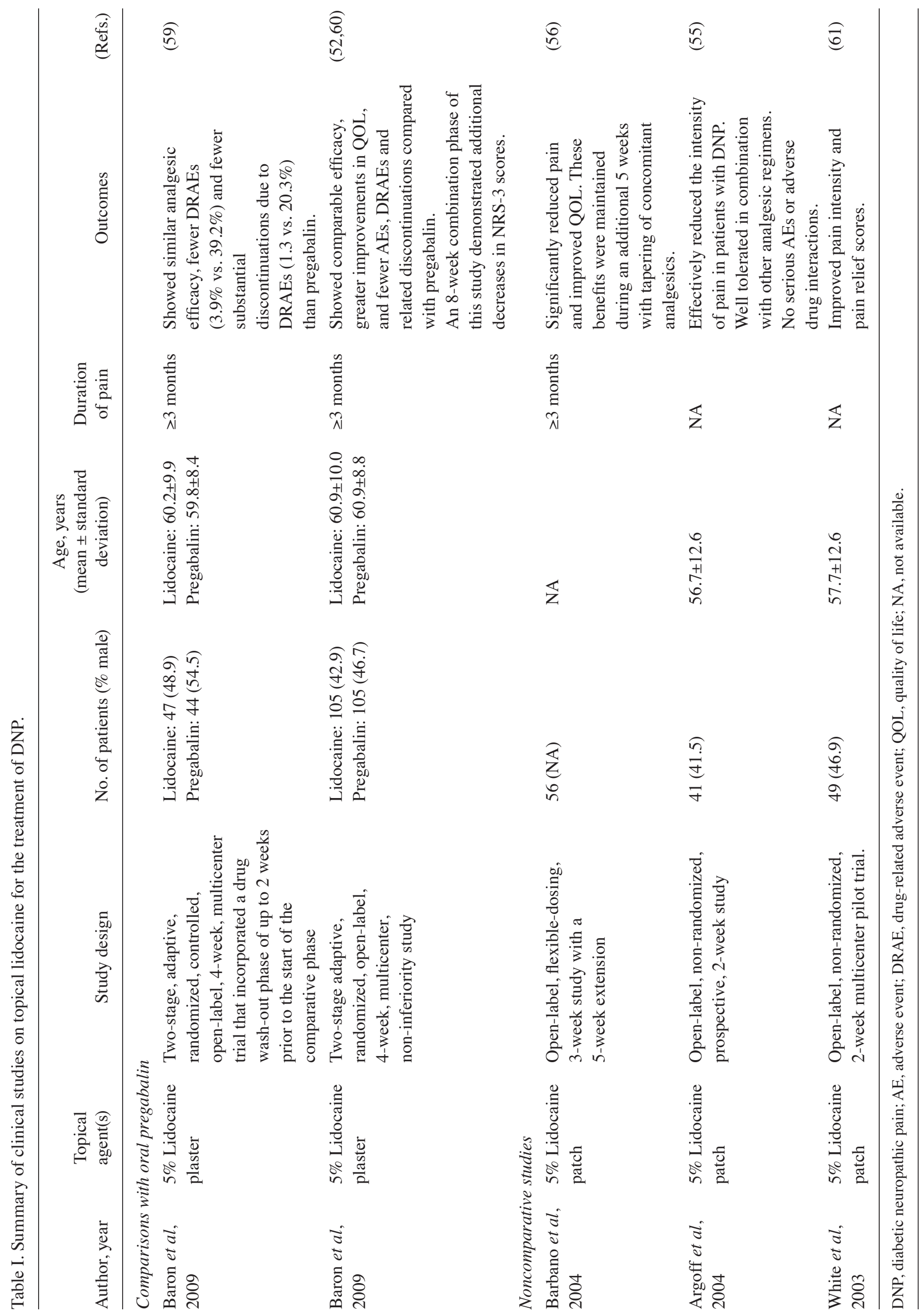


an additional 5-week period with a tapering of concomitant analgesics (56). A further two studies also included patients with PHN or lower back pain $(55,61)$. The $5 \%$ lidocaine patch could effectively reduce the intensity of pain in patients with various pain-related conditions, including DNP. A reduction in pain intensity was also observed with topical $5 \%$ lidocaine in a double-blind, randomized, placebo-controlled crossover study including patients with DNP (62). These results of clinical trials indicated that administration with a topical lidocaine $5 \%$ patch or plaster could relieve pain symptoms, including in DNP.

Topical capsaicin. Capsaicin, the active agent of the dried fruits or ground powder (paprika) of chili peppers, is a naturally occurring alkaloid (63). Capsaicin has been used with some success in the treatment of patients with DNP $(6,64)$. These effects are thought to be caused by selective binding to TRPV1 expressed on $A \delta$ and $C$ fibers (65). Once capsaicin binds to the receptor and the TRPV1 channel is opened, sodium and calcium influx and substance P release occurs (66). Repeated TRPV1 exposure to capsaicin causes substance P depletion and TRPV1 desensitization and defunctionalization (7). Two forms of capsaicin are available for DNP, a low-dose cream and a high-dose patch, both of which should be used under specialist supervision (67). Capsaicin creams with concentrations of 0.025-0.250\% must be applied multiple times per day for several weeks before analgesic effects become obvious (68). A single application of the Qutenza patch (capsaicin patch with an $8 \%$ concentration) following an appropriate local analgesia may provide up to 3 months of pain relief (23). Seven double-blind controlled studies and one open-label study of topical capsaicin in the treatment of DNP are summarized in Table II. No study specifically examined topical capsaicin as a monotherapy for DNP.

The action of low concentration capsaicin $(0.025$ or $0.075 \%$ ) in the treatment of DNP was reported in a series of the studies reviewed. The Capsaicin Study Group attempted to define the efficacy and safety of topical $0.075 \%$ capsaicin in patients with painful diabetic neuropathy. Improvement in pain relief, pain intensity and daily activities, including sleeping, walking and the ability to work and participate in recreational activities, were observed in significantly more patients treated with capsaicin than with a vehicle $(69,70)$. Compared with oral amitriptyline, topical $0.075 \%$ capsaicin cream was equally effective but considerably safer according to the results of a comparative study in patients with painful diabetic neuropathy (71). A double-blind, 8-week vehicle-controlled study with either $0.075 \%$ capsaicin cream or a vehicle cream over the painful area further confirmed the value and safety of capsaicin for pain relief in subjects with DNP $(72,73)$. By contrast, Chad et al (74) and Kulkantrakorn et al (75) observed that low concentration topical capsaicin had little effect in the treatment of DNP. After 4 weeks of $0.075 \%$ capsaicin cream treatment, there was no notable difference between capsaicin and the vehicle in terms of their beneficial effects on DNP (74). Meanwhile, $0.025 \%$ capsaicin gel was determined safe and well tolerated, but it did not provide significant pain relief in patients with DNP compared with a placebo (75). Due to the inconsistences between the aforementioned studies and their small sample sizes, it is difficult to conclude on the efficacy of low-concentration topical capsaicin in the treatment of DNP.
An $8 \%$ capsaicin patch, which is optimized for rapid delivery of a high concentration of capsaicin directly to the skin, contains $179 \mathrm{mg}$ or $8 \% \mathrm{w} / \mathrm{w}$ capsaicin. One double-blind study that assessed the efficacy of an $8 \%$ capsaicin patch compared with a placebo and one open-label study that provided long-term safety and tolerability data on patients with painful diabetic peripheral neuropathy (PDPN) were available. In the double-blind trial that assessed efficacy, 369 patients were randomized to an $8 \%$ capsaicin patch (Qutenza) or a placebo patch regimen. The capsaicin patch provided modest but statistically significant improvements in pain relief and improved sleep quality compared with the placebo patch, was well tolerated, and was not associated with any sensory deterioration or new safety concerns (76). In the 52-week open safety study, 468 DNP patients were randomized to a capsaicin $8 \%$ patch repeat treatment for 30 or 60 min plus standard of care (SOC), or SOC alone. No worsening in sensory perception tested with sharp, cold, warm or vibration stimuli was observed with topical capsaicin. Compared with SOC therapy alone, SOC plus capsaicin $8 \%$ patch repeat treatment over 52 weeks was well tolerated, had no neurological or negative functional effects and raised no new safety concerns (77). An article from the Drug and Therapeutics Bulletin proposed that there is a limited role for topical capsaicin in the treatment of DNP due to the uncertain efficacy of low-concentration topical capsaicin and the considerably more expensive cost of the $8 \%$ capsaicin patch compared with oral therapies (67). However, topical $0.075 \%$ capsaicin was recommended as a likely effective treatment option for DNP in the American Academy of Neurology evidence-based guidelines (78). A network meta-analysis performed in patients with PDPN suggested that the $8 \%$ capsaicin patch was only as effective as oral centrally acting agents but offered superior systemic tolerability benefits (18). Either low concentration or high concentration capsaicin may provide a degree of pain relief to some patients with neuropathic conditions that cause different degrees of pain. Further developments in methods of application and formulation may lead to improved clinical efficacy.

Topical amitriptyline. Amitriptyline is a tricyclic anti-depressant that acts centrally by blocking $\mathrm{Na}^{+}, \mathrm{K}^{+}$, and $\mathrm{Ca}^{2+}$ voltage-gated ion channels (79-81), inhibiting neuronal reuptake of norepinephrine and serotonin. It is effective in treating various types of neuropathic pain (82). A topical form of this drug has been investigated in certain previous studies for the treatment of DNP $(24,62,83)$ (Table III), however its adverse effects in oral administration have limited the higher doses needed to achieve adequate analgesia.

In a double-blind, randomized, placebo-controlled crossover study, 35 patients with postsurgical neuropathic pain, PHN or DNP were included to examine the analgesic effect of topical 5\% amitriptyline. This study failed to show efficacy of topical amitriptyline in alleviating neuropathic pain, though the results were based on a small sample size of DNP patients (62). Inconsistent with these results, a double-blind, 12 -week, randomized and non-inferiority trial revealed that topical $2 \%$ amitriptyline was effective in managing DNP. The results were similar to $0.75 \%$ capsaicin cream, with fewer adverse effects and improved patient compliance. However, the study only measured the median pain score using the visual 


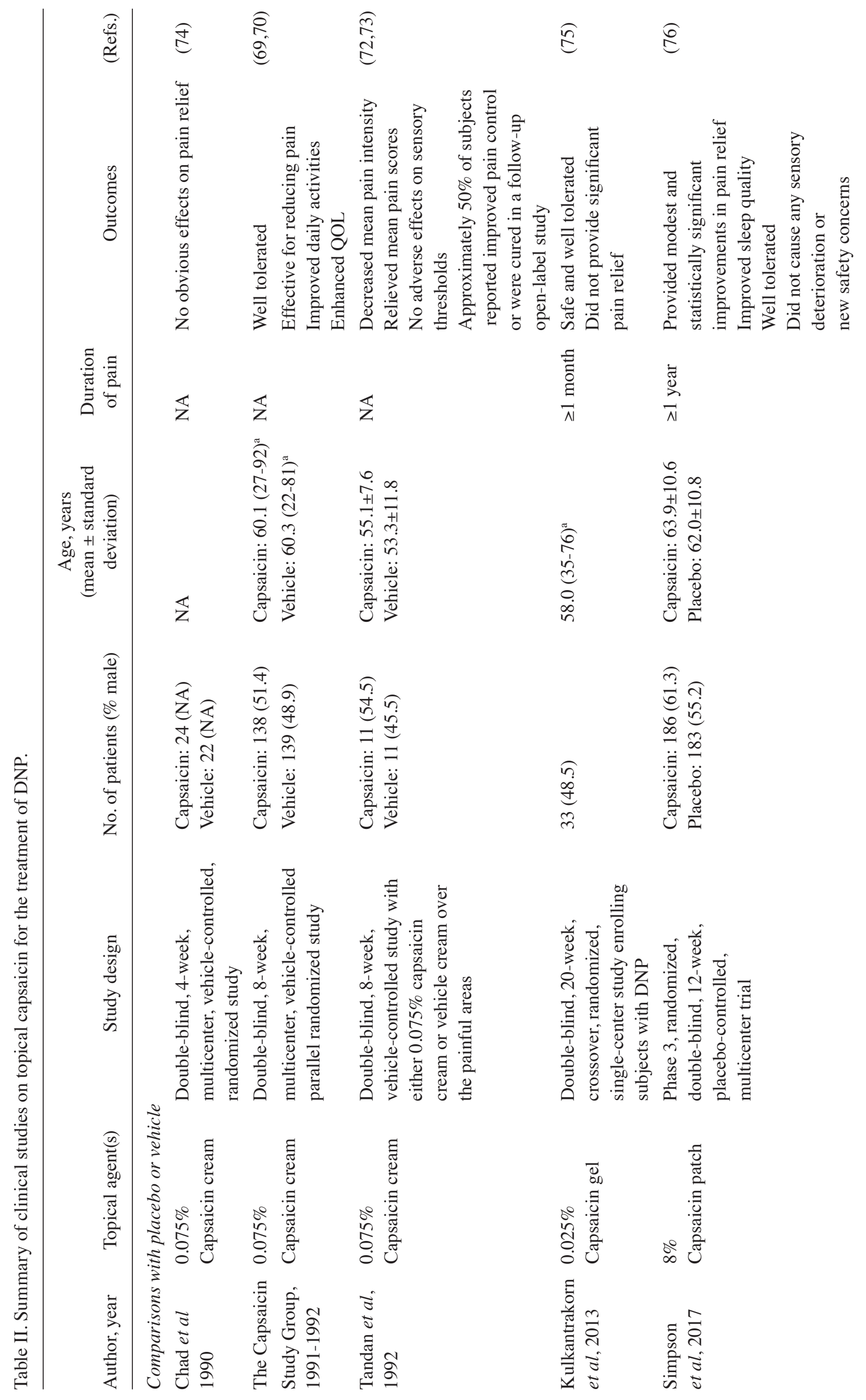




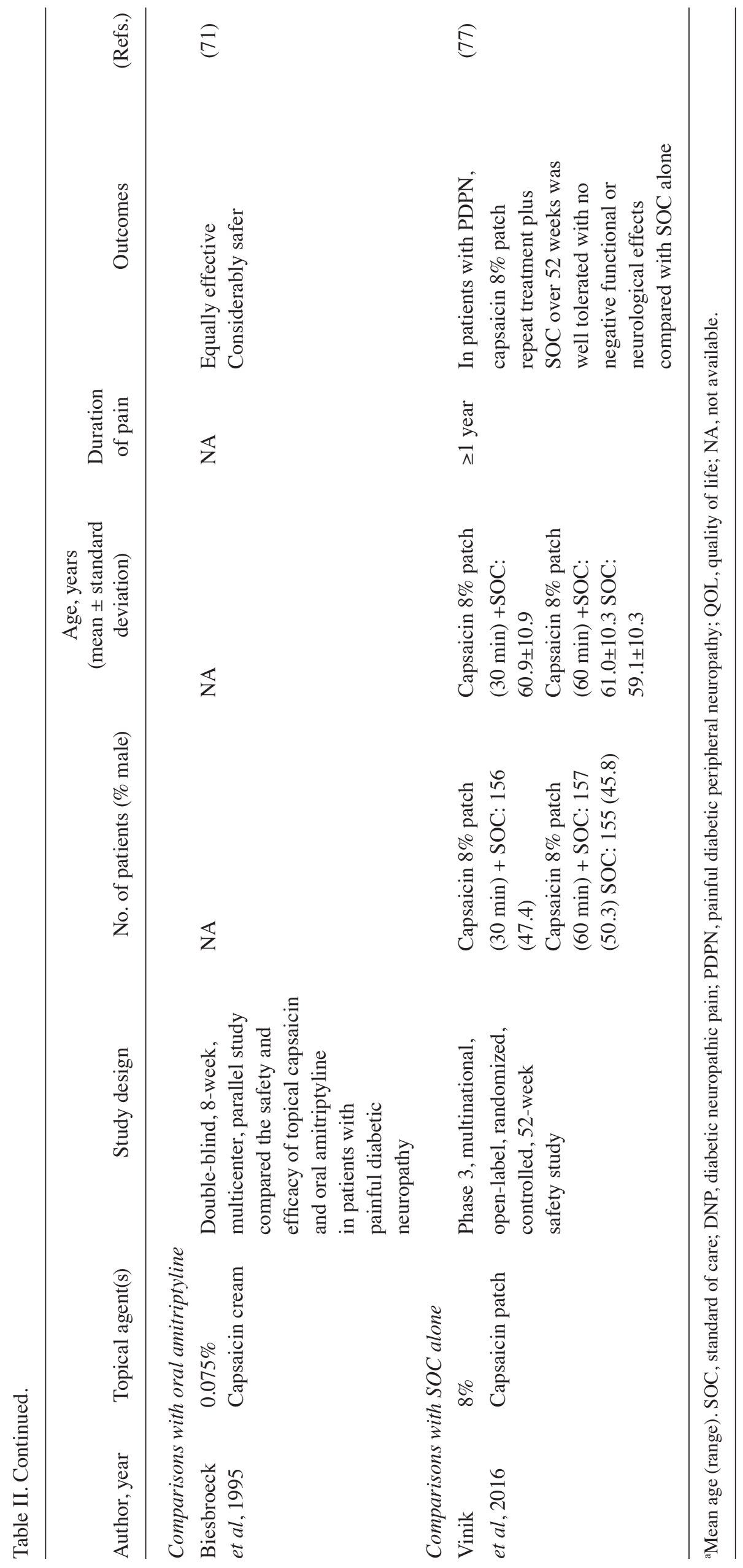




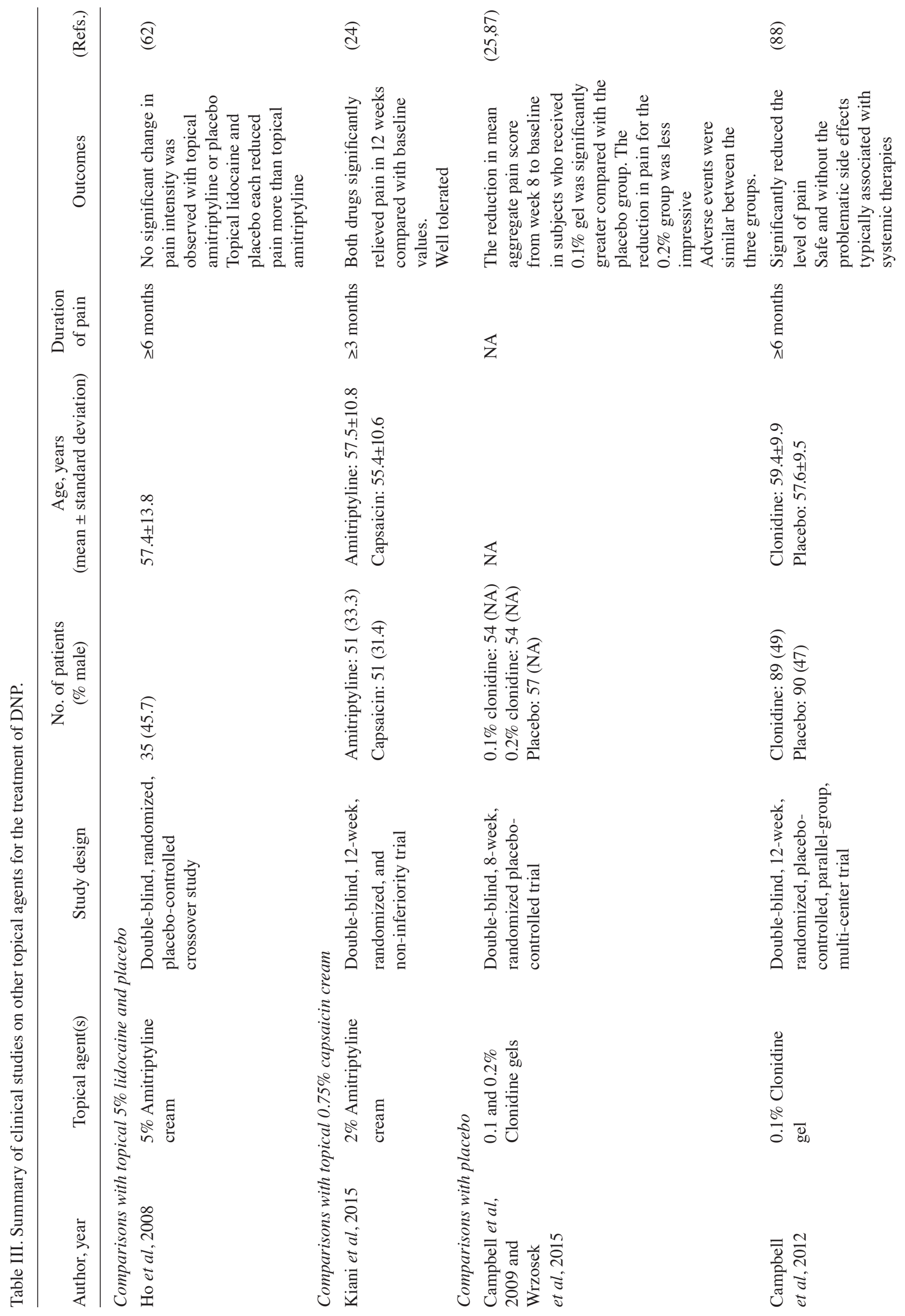




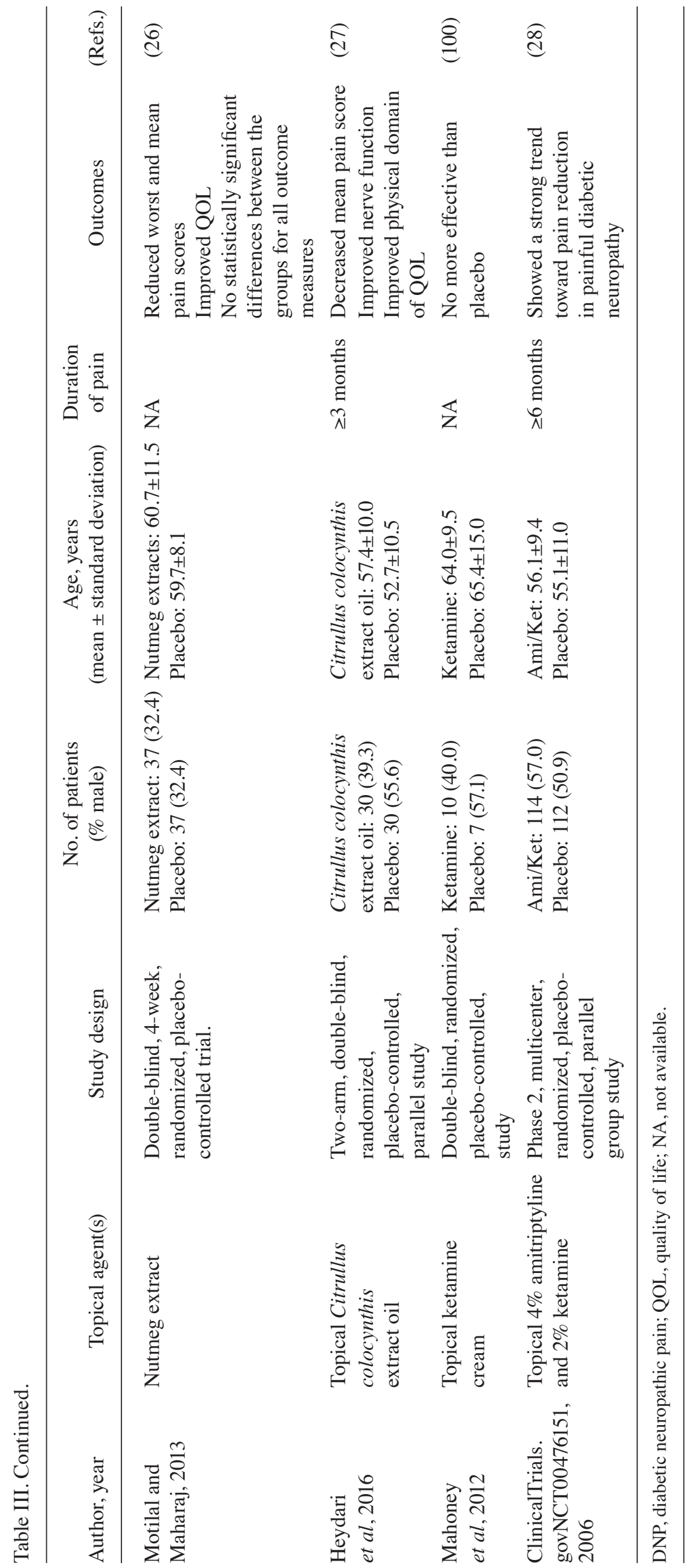


analogue scale (24). In addition, two cases treated with high doses of topical amitriptyline in neuropathic pain have been described to record the effect of topical amitriptyline (83). One of the cases reported a 39-year-old patient suffering from severe neuropathic pain in the feet and hands, due to type II diabetes mellitus (83). Following the use of 5\% amitriptyline, the pain in the hands was markedly relieved, and following application of amitriptyline $10 \%$ to the feet, a total reduction of pain occurred within $20 \mathrm{~min}$ and lasted the whole day. These effects reportedly lasted for 7 months and the patient did not experience any amitriptyline-related side effects (83). Amitriptyline could also improve the quality of sleep for the patients by reducing severe pins and needles in the feet at night (83). Therefore, high dose topical amitriptyline at 5 and $10 \%$ may be a useful adjunct to treat severe and intractable DNP. However at present, the therapeutic effect of amtriptyline on DNP is still unclear. Given the conflicting results of the reports, more studies are required to confirm the efficacy and safety of this topical compound as a treatment for DNP.

Topical clonidine. Clonidine is used to treat hypertension and other conditions, including intraocular pressure rise (84) and attention deficit syndrome (85), but it also has actions on sensory neurons by reducing excitability, acts on the microvasculature by improving blood flow, and acts on immune cells by reducing cytokine production (86). It is a presynaptic $\alpha 2$-adrenergic receptor agonist; thus adverse events associated with systemic use of this drug have limited its application. As such, topical clonidine formulations have been investigated in clinical studies. Two randomized placebo-controlled studies for the treatment of DNP have been conducted in the USA by Wrzosek et al (25) and Campbell et al (87) (Table III). Both studies evaluated the efficacy and safety of topical clonidine gel in DPDN patients. In the first of the studies, 54 patients received $0.1 \%$ clonidine gel $(650 \mu \mathrm{l})$ and another 54 patients were treated with $0.2 \%$ clonidine gel $(500 \mu \mathrm{l})$. The control group (57 patients) was given a placebo gel. Participants remained on their existing pain management treatments and these gels were applied to both feet twice daily for 2 weeks, then 3 times daily to a total of 8 weeks (25). Over the 8-week study interval, the reduction in mean aggregate pain score when compared with baseline in subjects who received $0.1 \%$ gel was significantly greater compared with the placebo group, while the reduction in pain for the $0.2 \%$ group was less notable. Investigators suggested the possible reason leading to such difference was the amount applied to the skin $(500 \mu \mathrm{l}$ at $0.2 \%$ vs. $650 \mu \mathrm{l}$ at $0.1 \%)$. Campbell et al (88) subsequently performed a 12 -week study to examine further the efficacy of topical $0.1 \%$ clonidine in treating DNP. In the clonidine group, the decrease in average pain from baseline to week 12 was greater than in the placebo group. For safety, only a low concentration of clonidine $(<10 \mathrm{pg} / \mathrm{ml})$ was aimed for in the plasma during topical application (88), and it was considerably lower than the threshold for treating hypertension, suggesting that topical use will be associated with few of the adverse effects of clonidine. The results of these two clinical trials indicated that the topical use of clonidine may relieve DNP, but it is not known from these studies if clonidine is safe for long-term use. The use of active treatment rather than placebo may reveal more information about the comparative efficacy of topical clonidine vs. other drugs.
Topical nutmeg extracts. Nutmeg is the dried kernel of the broadly ovoid seed of Myristica fragrans. Certain animal studies support nutmeg as a potential analgesic for DNP $(89,90)$. A double-blind, 4-week, randomized, placebo-controlled trial further tested the ability of topical nutmeg extracts to reduce pain or improve QOL in patients with DNP (26) (Table III). A total of 74 participants who met the criteria for painful diabetic neuropathy were recruited. Subjects were instructed to apply four sprays of either topical nutmeg extract or placebo to the affected area 3 times a day followed by gentle massage for 4 weeks. The topical nutmeg extract preparation significantly reduced the worst and mean pain scores, and improved QOL by the end of the 4-week study, but the effects were not superior to the placebo. Due to the limited clinical research data, it is not possible to conclude on the efficacy of topical nutmeg extracts for the treatment of painful diabetic neuropathy.

Topical Citrullus colocynthis (bitter apple) extract oil. Bitter apple, or Citrullus colocynthis, is a medicinal plant originating from Africa and Asia, where it has traditionally been used for various medicinal purposes, including pain relief (91). Citrullus colocynthis has been demonstrated to have anesthetic (92), anti-oxidant (93) and anti-ulcerogenic effects (94). These properties are considered important in the pathophysiology and/or progression of diabetic neuropathy. Heydari et al (27) examined its efficacy and safety in DNP patients (Table III): 60 patients with DNP were randomized to receive topical Citrullus colocynthis or placebo twice daily for 3 months. There was a significantly greater decrease in mean pain score after 3 months in the Citrullus colocynthis group than with the placebo. It also significantly improved nerve function and the mean score in the physical aspect of QOL (95). Therefore, topical Citrullus colocynthis may be a potential agent for use in the treatment of DNP and should be investigated further in studies with larger sample sizes performed over longer duration.

Topical ketamine. Ketamine is a non-barbiturate anesthetic agent that acts through blocking glutamate receptors, including peripheral $\mathrm{N}$-methyl-D-aspartate receptors and $\alpha$-amino-3hydroxy-5-methylisoxazole-4-proprionic acid (86,96-98), and also as an inhibitor of voltage-gated $\mathrm{Na}^{+}$and $\mathrm{K}^{+}$ion channels (99). A recent study evaluated the effects of topical ketamine in relieving DNP (Table III): 17 patients with DNP were randomly divided into a $5 \%$ ketamine cream group or a placebo group. The 5\% topical ketamine cream was no more effective than the placebo in relieving pain caused by diabetic neuropathy (100). A limitation of this study was the sample size; therefore the clinical efficacy of ketamine needs to be further evaluated.

Compounded topical agents. Mixtures of two or more medicated forms of compounded topical agent have been developed into potentially valuable treatment options for DNP. The authors of the current study concluded that these may be effective due to the multiple complementary effects at lower doses of each individual medication. It is apparent that only one study with compounded topical agents has been performed in patients with DNP only (28) (Table III); 4 other related studies also selected patients with other types 
of neuropathic pain $(96,101-103)$. In a pilot study and its follow-up studies of mixed neuropathic pain, including DNP, patients who were treated with topical low-dose combinations of amitriptyline (1-2\%) and ketamine (0.5-1\%) did not experience significant pain relief effect compared with those receiving placebo for $1-3$ weeks $(96,101)$. However, the treatment was associated with long-term perceived analgesic effectiveness for 12 months (102). As for higher concentrations of these combined agents (4\% amitriptyline and 2\% ketamine), a phase 2, multi-center, double-blind, randomized, placebo-controlled, parallel group study indicated a trend towards pain reduction in painful diabetic neuropathy $(16,28)$. Somberg and Molnar (103) conducted a retrospective study on the analgesic activity of a topical (TT-CTAC) cream in patients with diabetic neuropathy and other chronic pain conditions. Two versions of TT-CTAC cream were evaluated: cream $6 \mathrm{~B}$ and cream $7 \mathrm{~B}$. Both creams contain ketamine (10\%), baclofen (2\%), gabapentin (6\%), amitriptyline (4\%), bupivacaine $(2 \%)$ and clonidine $(0.2 \%)$. Additionally, one cream (7B) contained nifedipine $(2 \%)$. Both creams provided considerable pain relief in the majority of the patients studied and were thus suggested to be useful modalities for pain therapy. Due to a lack of comparative studies between compounded topical agents and single drugs for DNP, it is not possible to conclude on the drug cost, efficacy and side effects of compounded agent compared with single-agent topical treatment of DNP. However, given the advantages of formula diversity, drug economy and safety, it may be that compounded topical agents have promising market prospects and clinical application value.

\section{Conclusion and perspectives}

DNP is a distressing consequence of diabetes that may be present in as many as one in five diabetic patients (104). The pain may be severe and management challenging. Oral treatment is the most frequently used and among the most convenient for pain medication, but is also associated with risk of adverse systematic effects $(105,106)$, particularly in vulnerable patients with multiple comorbidities and altered pharmacokinetics and pharmacodynamics that may alter drug metabolism (107). This may decrease the patient's compliance. With this concern for the systematic side effects of oral agents, topical preparations for the treatment of DNP have gained increasing interest. Numerous clinical studies have evaluated the analgesic effect and safety of various topical agents, including topical anesthetic agent lidocaine, general anesthetic agent ketamine, antidepressant agent amitriptyline, $\alpha 2$ adrenergic agent clonidine, capsaicin, nutmeg extracts, Citrullus colocynthis extract oil, and some compounded topical analgesics. Overall topical agents are easy to administer, offer significant improvement in patient compliance and reduce the burden of multiple drug regimens.

For the topical treatments of DNP discussed here, a 5\% lidocaine patch has been found to significantly reduce pain in DNP patients with 2-3 weeks of treatment and the benefits were maintained during an additional 5 weeks with tapering of concomitant analgesics. Furthermore, the 5\% lidocaine plaster was reported to exhibit similar analgesic efficacy and fewer DRAEs compared with oral pregabalin. It is difficult to draw conclusions about the efficacy of low-concentration topical capsaicin in the treatment of DNP due to the inconsistencies among related research findings. The $8 \%$ capsaicin patch was as effective as oral centrally acting agents but offered systemic tolerability benefits, provided modest but statistically significant improvements in pain relief and was well tolerated. There is conflicting evidence regarding the effect of topical amitriptyline and it needs to be confirmed by further studies. Topical clonidine, nutmeg extract preparation, Citrullus colocynthis extract and some compounded topical agents may provide significant though less notable or only long-term improvements in pain relief. For instance, study demonstrated that $5 \%$ topical ketamine cream was no more effective than a placebo in relieving pain caused by diabetic neuropathy, but the study only included 17 patients with DNP.

Since published studies suggest that these drugs have the potential to be a valuable additional option for the management of DNP, with adequate safety and continuous long-term treatment efficacy, these topical drugs should be given further consideration for the treatment of DNP. Furthermore, as described in several studies, compounded agents are not only effective but also safe for patients with DNP. Therefore, the use of low-dose, complementary therapies with compounded agents is another area worthy of further investigation. Additionally, topical drugs that act on different targets in the process of DNP, including anti-inflammatory and abnormal ectopic discharge therapies, or anti-oxidant and AGE/RAGE therapies, should be studied in the future.

\section{Acknowledgements}

Not applicable.

\section{Funding}

The authors would like to thank the Natural Science Foundation of China (grant no. 81603171), the Natural Science Foundation of Hunan Province (grant no. 2018JJ3743) and the Open-End Fund for the Valuable and Precision Instruments of Central South University (grant no. CSUZC201734) for the financial support.

\section{Availability of data and materials}

Not applicable.

\section{Authors' contributions}

PFF, XDY and YYY designed the present study. XDY, PFF, DXX and YYY collected the literature and performed the literature review. XDY and YYY wrote the manuscript. YYY, PFF and XDY revised the manuscript.

\section{Ethics approval and consent to participate}

Not applicable.

\section{Patient consent for publication}

Not applicable. 


\section{Competing interests}

The authors have no competing interests to declare.

\section{References}

1. International Diabetes Federation (IDF). IDF Diabetes Atlas 7th edition, 2017.

2. Edwards JL, Vincent AM, Cheng HT and Feldman EL: Diabetic neuropathy: Mechanisms to management. Pharmacol Ther 120 $1-34,2008$

3. Harati Y: Diabetic neuropathies: Unanswered questions. Neurol Clin 25: 303-317, 2007.

4. Farmer KL, Li C and Dobrowsky RT: Diabetic peripheral neuropathy: Should a chaperone accompany our therapeutic approach? Pharmacol Rev 64: 880-900, 2012.

5. Spallone V, Lacerenza M, Rossi A, Sicuteri R and Marchettini P: Painful diabetic polyneuropathy: Approach to diagnosis and management. Clin J Pain 28: 726-743, 2012.

6. Snyder MJ, Gibbs LM and Lindsay TJ: Treating painful diabetic peripheral neuropathy: An update. Am Fam Physician 94 227-234, 2016.

7. Schreiber AK, Nones CF, Reis RC, Chichorro JG and Cunha JM: Diabetic neuropathic pain: Physiopathology and treatment World J Diabetes 6: 432-444, 2015.

8. Tesfaye S, Vileikyte L, Rayman G, Sindrup SH, Perkins BA, Baconja M, Vinik AI and Boulton AJ; Toronto Expert Panel on Diabetic Neuropathy: Painful diabetic peripheral neuropathy: Consensus recommendations on diagnosis, assessment and management. Diabetes Metab Res Rev 27: 629-638, 2011.

9. Jane SW, Lin MS, Chiu WN, Beaton RD and Chen MY Prevalence, discomfort and self-relief behaviours of painful diabetic neuropathy in Taiwan: A cross-sectional study. BMJ Open 6: e11897, 2016.

10. Tesfaye S, Boulton AJ and Dickenson AH: Mechanisms and management of diabetic painful distal symmetrical polyneuropathy. Diabetes Care 36: 2456-2465, 2013.

11. Gore M, Brandenburg NA, Dukes E, Hoffman DL, Tai KS and Stacey B: Pain severity in diabetic peripheral neuropathy is associated with patient functioning, symptom levels of anxiety and depression, and sleep. J Pain Symptom Manage 30: 374-385, 2005.

12. Vileikyte L, Leventhal H, Gonzalez JS, Peyrot M, Rubin RR, Ulbrecht JS, Garrow A, Waterman C, Cavanagh PR and Boulton AJ: Diabetic peripheral neuropathy and depressive symptoms: The association revisited. Diabetes Care 28: 2378-2383, 2005.

13. Sadosky A, McDermott AM, Brandenburg NA and Strauss M: A review of the epidemiology of painful diabetic peripheral neuropathy, postherpetic neuralgia, and less commonly studied neuropathic pain conditions. Pain Pract 8: 45-56, 2008.

14. Ziegler D: Painful diabetic neuropathy: Treatment and future aspects. Diabetes Metab Res Rev 24 (Suppl 1): S52-S57, 2008.

15. Kaku M, Vinik A and Simpson DM: Pathways in the diagnosis and management of diabetic polyneuropathy. Curr Diab Rep 15: $609,2015$.

16. Sawynok J and Zinger C: Topical amitriptyline and ketamine for post-herpetic neuralgia and other forms of neuropathic pain Expert Opin Pharmacother 17: 601-609, 2016.

17. Ziegler D and Fonseca V: From guideline to patient: A review of recent recommendations for pharmacotherapy of painful diabetic neuropathy. J Diabetes Complications 29: 146-156, 2015.

18. van Nooten F, Treur M, Pantiri K, Stoker M and Charokopou M: Capsaicin $8 \%$ patch versus oral neuropathic pain medications for the treatment of painful diabetic peripheral neuropathy: A systematic literature review and network meta-analysis. Clin Ther 39: 787-803.e18, 2017.

19. Argoff CE: Topical analgesics in the management of acute and chronic pain. Mayo Clin Proc 88: 195-205, 2013.

20. Jorge LL, Feres CC and Teles VE: Topical preparations for pain relief: Efficacy and patient adherence. J Pain Res 4: 11-24, 2010.

21. Derry S, Rice AS, Cole P, Tan T and Moore RA: Topical capsaicin (high concentration) for chronic neuropathic pain in adults. Cochrane Database Syst Rev 1: CD007393, 2017.

22. Mick G and Correa-Illanes G: Topical pain management with the 5\% lidocaine medicated plaster-a review. Curr Med Res Opin 28: 937-951, 2012.
23. Mou J, Paillard F, Turnbull B, Trudeau J, Stoker M and Katz NP: Qutenza (capsaicin) 8\% patch onset and duration of response and effects of multiple treatments in neuropathic pain patients. Clin J Pain 30: 286-294, 2014

24. Kiani J, Ahmad Nasrollahi S, Esna-Ashari F, Fallah P and Sajedi F: Amitriptyline 2\% cream vs. capsaicin $0.75 \%$ cream in the treatment of painful diabetic neuropathy (Double blind, randomized clinical trial of efficacy and safety). Iran J Pharm Res 14: 1263-1268, 2015.

25. Wrzosek A, Woron J, Dobrogowski J, Jakowicka-Wordliczek J and Wordliczek J: Topical clonidine for neuropathic pain. Cochrane Database Syst Rev 8: CD010967, 2015.

26. Motilal S and Maharaj RG: Nutmeg extracts for painful diabetic neuropathy: A randomized, double-blind, controlled study. J Altern Complement Med 19: 347-352, 2013.

27. Heydari M, Homayouni K, Hashempur MH and Shams M: Topical Citrullus colocynthis (bitter apple) extract oil in painful diabetic neuropathy: A double-blind randomized placebo-controlled clinical trial. J Diabetes 8: 246-252, 2016.

28. A study of the efficacy and safety of amitriptyline/ketamine topical cream in patients with diabetic peripheral neuropathy. ClinicalTrials.gov NCT00476151, 2006.

29. Casale R, Symeonidou Z and Bartolo M: Topical treatments for localized neuropathic pain. Curr Pain Headache Rep 21: 15, 2017.

30. Sloan G, Shillo P, Selvarajah D, Wu J, Wilkinson ID, Tracey I, Anand $\mathrm{P}$ and Tesfaye S: A new look at painful diabetic neuropathy. Diabetes Res Clin Pract 144: 177-191, 2018.

31. Dewanjee S, Das S, Das AK, Bhattacharjee N, Dihingia A, Dua TK, Kalita J and Manna P: Molecular mechanism of diabetic neuropathy and its pharmacotherapeutic targets. Eur J Pharmacol 833: 472-523, 2018.

32. Dobretsov M, Hastings SL, Romanovsky D, Stimers JR and Zhang JM: Mechanical hyperalgesia in rat models of systemic and local hyperglycemia. Brain Res 960: 174-183, 2003.

33. Oyibo SO, Prasad YD, Jackson NJ, Jude EB and Boulton AJ: The relationship between blood glucose excursions and painful diabetic peripheral neuropathy: A pilot study. Diabet Med 19: 870-873, 2002

34. Morley GK, Mooradian AD, Levine AS and Morley JE: Mechanism of pain in diabetic peripheral neuropathy. Effect of glucose on pain perception in humans. Am J Med 77: 79-82, 1984.

35. Lee JH, Cox DJ, Mook DG and McCarty RC: Effect of hyperglycemia on pain threshold in alloxan-diabetic rats. Pain 40: 105-107, 1990.

36. Dyck PJ, Litchy WJ, Lehman KA, Hokanson JL, Low PA and O'Brien PC: Variables influencing neuropathic endpoints: The rochester diabetic neuropathy study of healthy subjects. Neurology 45: 1115-1121, 1995.

37. Romanovsky D, Wang J, Al-Chaer ED, Stimers JR and Dobretsov M: Comparison of metabolic and neuropathy profiles of rats with streptozotocin-induced overt and moderate insulinopenia. Neuroscience 170: 337-347, 2010.

38. Peppa M, Stavroulakis P and Raptis SA: Advanced glycoxidation products and impaired diabetic wound healing. Wound Repair Regen 17: 461-472, 2009.

39. Babizhayev MA, Strokov IA, Nosikov VV, Savel'Yeva EL, Sitnikov VF, Yegorov YE and Lankin VZ: The role of oxidative stress in diabetic neuropathy: Generation of free radical species in the glycation reaction and gene polymorphisms encoding antioxidant enzymes to genetic susceptibility to diabetic neuropathy in population of type i diabetic patients. Cell Biochem Biophys 71: 1425-1443, 2015

40. Oates PJ: Polyol pathway and diabetic peripheral neuropathy. Int Rev Neurobiol 50: 325-392, 2002.

41. Obrosova IG: How does glucose generate oxidative stress in peripheral nerve Int Rev Neurobiol 50: 3-35, 2002.

42. Obrosova IG: Diabetes and the peripheral nerve. Biochim Biophys Acta 1792: 931-940, 2009.

43. Schemmel KE, Padiyara RS and D'Souza JJ: Aldose reductase inhibitors in the treatment of diabetic peripheral neuropathy: A review. J Diabetes Complications 24: 354-360, 2010.

44. Fuchs D, Birklein F, Reeh PW and Sauer SK: Sensitized peripheral nociception in experimental diabetes of the rat. Pain 151: 496-505, 2010

45. Bachewal P, Gundu C, Yerra VG, Kalvala AK, Areti A and Kumar A: Morin exerts neuroprotection via attenuation of ROS induced oxidative damage and neuroinflammation in experimental diabetic neuropathy. Biofactors 44: 109-122, 2018 . 
46. Tobon-Velasco JC, Cuevas E and Torres-Ramos MA: Receptor for AGEs (RAGE) as mediator of NF-kB pathway activation in neuroinflammation and oxidative stress. CNS Neurol Disord Drug Targets 13: 1615-1626, 2014.

47. Gao X, Wu B, Fu Z, Zhang Z and Xu G: Carvedilol abrogates hypoxia-induced oxidative stress and neuroinflammation in microglial BV2 cells. Eur J Pharmacol 814: 144-150, 2017.

48. Dworkin RH: An overview of neuropathic pain: Syndromes, symptoms, signs, and several mechanisms. Clin J Pain 18 343-349, 2002 .

49. Djouhri L, Fang X, Koutsikou S and Lawson SN: Partial nerve injury induces electrophysiological changes in conducting (uninjured) nociceptive and nonnociceptive DRG neurons: Possible relationships to aspects of peripheral neuropathic pain and paresthesias. Pain 153: 1824-1836, 2012.

50. Aslam A, Singh J and Rajbhandari S: Pathogenesis of painful diabetic neuropathy. Pain Res Treat 2014: 412041, 2014.

51. Rahman MH, Jha MK and Suk K: Evolving insights into the pathophysiology of diabetic neuropathy: Implications of malfunctioning glia and discovery of novel therapeutic targets. Curr Pharm Des 22: 738-757, 2016.

52. Baron R, Mayoral V, Leijon G, Binder A, Steigerwald I and Serpell M: 5\% lidocaine medicated plaster versus pregabalin in post-herpetic neuralgia and diabetic polyneuropathy: An open-label, non-inferiority two-stage RCT study. Curr Med Res Opin 25: 1663-1676, 2009.

53. Krumova EK, Zeller M, Westermann A and Maier C: Lidocaine patch $(5 \%)$ produces a selective, but incomplete block of $\mathrm{A} \delta$ and C fibers. Pain 153: 273-280, 2012.

54. Herrmann DN, Barbano RL, Hart-Gouleau S, Pennella-Vaughan J and Dworkin RH: An open-label study of the lidocaine patch $5 \%$ in painful idiopathic sensory polyneuropathy. Pain Med 6 379-384, 2005

55. Argoff CE, Galer BS, Jensen MP, Oleka N and Gammaitoni AR: Effectiveness of the lidocaine patch $5 \%$ on pain qualities in three chronic pain states: Assessment with the neuropathic pain scale. Curr Med Res Opin 20 (Suppl 2): S21-S28, 2004.

56. Barbano RL, Herrmann DN, Hart-Gouleau S, Pennella-Vaughan J, Lodewick PA and Dworkin RH Effectiveness, tolerability, and impact on quality of life of the $5 \%$ lidocaine patch in diabetic polyneuropathy. Arch Neurol 61: 914-918, 2004

57. Devers A and Galer BS: Topical lidocaine patch relieves a variety of neuropathic pain conditions: An open-label study. Clin J Pain 16: 205-208, 2000

58. Wolff RF, Bala MM, Westwood M, Kessels AG and Kleijnen J: $5 \%$ lidocaine medicated plaster in painful diabetic periphera neuropathy (DPN): A systematic review. Swiss Med Wkly 140: 297-306, 2010

59. Baron R, Mayoral V, Leijon G, Binder A, Steigerwald I and Serpell M: Efficacy and safety of 5\% lidocaine (lignocaine) medicated plaster in comparison with pregabalin in patients with postherpetic neuralgia and diabetic polyneuropathy: Interim analysis from an open-label, two-stage adaptive, randomized, controlled trial. Clin Drug Investig 29: 231-241, 2009.

60. Baron R, Mayoral V, Leijon G, Binder A, Steigerwald I and Serpell M: Efficacy and safety of combination therapy with 5\% lidocaine medicated plaster and pregabalin in post-herpetic neuralgia and diabetic polyneuropathy. Curr Med Res Opin 25: $1677-1687,2009$

61. White WT, Patel N, Drass M and Nalamachu S: Lidocaine patch 5\% with systemic analgesics such as gabapentin: A rational polypharmacy approach for the treatment of chronic pain. Pain Med 4: 321-330, 2003

62. Ho KY, Huh BK, White WD, Yeh CC and Miller EJ: Topical amitriptyline versus lidocaine in the treatment of neuropathic pain. Clin J Pain 24: 51-55, 2008.

63. Zheng J, Zheng S, Feng Q, Zhang Q and Xiao X: Dietary capsaicin and its anti-obesity potency: From mechanism to clinical implications. Biosci Rep 37: pii: BSR20170286, 2017.

64. Musharraf MU, Ahmad Z and Yaqub Z: Comparison of topical capsaicin and topical turpentine Oil for treatment of painful diabetic neuropathy. J Ayub Med Coll Abbottabad 29: 384-387, 2017.

65. Mitchell K, Bates BD, Keller JM, Lopez M, Scholl L, Navarro J, Madian N, Haspel G, Nemenov MI and Iadarola MJ: Ablation of rat TRPV1-expressing Adelta/C-fibers with resiniferatoxin: Analysis of withdrawal behaviors, recovery of function and molecular correlates. Mol Pain 6: 94, 2010
66. Fattori V, Hohmann MS, Rossaneis AC, Pinho-Ribeiro FA and Verri WA: Capsaicin: Current understanding of its mechanisms and therapy of pain and other pre-clinical and clinical uses. Molecules 21: pii: E844, 2016.

67. What role for capsaicin in diabetic peripheral neuropathy? Drug Ther Bull 54: 90-93, 2016.

68. Rosenberg CJ and Watson JC: Treatment of painful diabetic peripheral neuropathy. Prosthet Orthot Int 39: 17-28, 2015.

69. Treatment of painful diabetic neuropathy with topical capsaicin. A multicenter, double-blind, vehicle-controlled study. The Capsaicin Study Group. Arch Intern Med 151: 2225-2229, 1991.

70. Effect of treatment with capsaicin on daily activities of patients with painful diabetic neuropathy. The Capsaicin Study Group. Diabetes Care 15: 159-165, 1992.

71. Biesbroeck R, Bril V, Hollander P, Kabadi U, Schwartz S, Singh SP, Ward WK and Bernstein JE: A double-blind comparison of topical capsaicin and oral amitriptyline in painful diabetic neuropathy. Adv Ther 12: 111-120, 1995.

72. Tandan R, Lewis GA, Badger GB and Fries TJ: Topical capsaicin in painful diabetic neuropathy. Effect on sensory function. Diabetes Care 15: 15-18, 1992.

73. Tandan R, Lewis GA, Krusinski PB, Badger GB and Fries TJ: Topical capsaicin in painful diabetic neuropathy. Controlled study with long-term follow-up. Diabetes Care 15: 8-14, 1992

74. Chad DA, Aronin N, Lundstrom R, McKeon P, Ross D, Molitch M, Schipper HM, Stall G, Dyess E and Tarsy D: Does capsaicin relieve the pain of diabetic neuropathy? Pain 42: 387-388, 1990

75. Kulkantrakorn K, Lorsuwansiri C and Meesawatsom P: $0.025 \%$ capsaicin gel for the treatment of painful diabetic neuropathy: A randomized, double-blind, crossover, placebo-controlled trial. Pain Pract 13: 497-503, 2013.

76. Simpson DM, Robinson-Papp J, Van J, Stoker M, Jacobs H, Snijder RJ, Schregardus DS, Long SK, Lambourg B and Katz N: Capsaicin 8\% patch in painful diabetic peripheral neuropathy: A randomized, double-blind, placebo-controlled study. J Pain 18: 42-53, 2017

77. Vinik AI, Perrot S, Vinik EJ, Pazdera L, Jacobs H, Stoker M, Long SK, Snijder RJ, van der Stoep M, Ortega E and Katz N: Capsaicin $8 \%$ patch repeat treatment plus standard of care (SOC) versus SOC alone in painful diabetic peripheral neuropathy: A randomised, 52-week, open-label, safety study. BMC Neurol 16: 251, 2016.

78. Bril V, England J, Franklin GM, Backonja M, Cohen J, Del Toro D, Feldman E, Iverson DJ, Perkins B, Russell JW, et al: Evidence-based guideline: Treatment of painful diabetic neuropathy: Report of the American academy of neurology, the American association of neuromuscular and electrodiagnostic medicine and the American academy of physical medicine and rehabilitation. PM R 3: 345-352, 2011.

79. Pancrazio JJ, Kamatchi GL, Roscoe AK and Lynch CR III: Inhibition of neuronal $\mathrm{Na}+$ channels by antidepressant drugs. J Pharmacol Exp Ther 284: 208-214, 1998.

80. Nicholson GM, Blanche T, Mansfield K and Tran Y: Differential blockade of neuronal voltage-gated $\mathrm{Na}(+)$ and $\mathrm{K}(+)$ channels by antidepressant drugs. Eur J Pharmacol 452: 35-48, 2002.

81. Joshi PG, Singh A and Ravichandra B: High concentrations of tricyclic antidepressants increase intracellular $\mathrm{Ca} 2+$ in cultured neural cells. Neurochem Res 24: 391-398, 1999.

82. Watson CP: The treatment of neuropathic pain: Antidepressants and opioids. Clin J Pain 16 (2 Suppl): S49-S55, 2000.

83. Kopsky DJ and Hesselink JM: High doses of topical amitriptyline in neuropathic pain: Two cases and literature review. Pain Pract 12: 148-153, 2012

84. Zeraatian S, Zakeri H, Boroojeny SB, Hourang $\mathrm{MH}$, Ghaffarpasand $\mathrm{F}$ and Fard MM: Effect of oral clonidine on acute intraocular pressure rise after phacoemulsification: A prospective double-blind, randomized, clinical trial. J Ocul Pharmacol Ther 27: 293-297, 2011.

85. Otasowie J, Castells X, Ehimare UP and Smith $\mathrm{CH}$ : Tricyclic antidepressants for attention deficit hyperactivity disorder (ADHD) in children and adolescents. Cochrane Database Syst Rev 9: CD006997, 2014

86. Sawynok J: Topical analgesics for neuropathic pain: Preclinical exploration, clinical validation, future development. Eur J Pain 18: 465-481, 2014.

87. Campbell C, Campbell J, Schmidt W, Brady K and Stouch B: Topical clonidine gel reduces pain caused by diabetic neuropathy: Results of a multicenter, placebo-controlled clinical trial. J Pain 10 (Suppl): S55, 2009. 
88. Campbell CM, Kipnes MS, Stouch BC, Brady KL, Kelly M, Schmidt WK, Petersen KL, Rowbotham MC and Campbell JN: Randomized control trial of topical clonidine for treatment of painful diabetic neuropathy. Pain 153: 1815-1823, 2012.

89. Grover JK, Khandkar S, Vats V, Dhunnoo Y and Das D: Pharmacological studies on myristica fragrans-antidiarrheal, hypnotic, analgesic and hemodynamic (blood pressure) parameters. Methods Find Exp Clin Pharmacol 24: 675-680, 2002

90. Hayfaa AA, Sahar AM and Awatif MA: Evaluation of analgesic activity and toxicity of alkaloids in myristica fragrans seeds in mice. J Pain Res 6: 611-615, 2013.

91. Forouzanfar F and Hosseinzadeh $\mathrm{H}$ : Medicinal herbs in the treatment of neuropathic pain: A review. Iran J Basic Med Sci 21: 347-358, 2018.

92. Ramanathan T, Gurudeeban S and Satyavani K: Local anesthetic effect of citrullus colocynthis on rana hexadactyla. Res J Med Plant 5: 338-342, 2011.

93. Kumar S, Kumar D, Manjusha, Saroha K, Singh N and Vashishta B: Antioxidant and free radical scavenging potential of citrullus colocynthis (L.) schrad. Methanolic fruit extract. Acta Pharm 58: 215-220, 2008.

94. Reddy VP, Sudheshna G, Shaik A, Saran SS, Kumar SN, Ram CR and Reddy KR: Evaluation of antiulcer activity of Citrullus colocynthis fruit against pylorus ligation induced ulcers in male Wistar rats. Int J Pharm Pharm Sci 4: 446-451, 2012.

95. Nedjat S, Montazeri A, Holakouie K, Mohammad K and Majdzadeh R: Psychometric properties of the Iranian interview-administered version of the world health organization's quality of life questionnaire (WHOQOL-BREF): A population-based study. BMC Health Serv Res 8: 61, 2008.

96. Lynch ME, Clark AJ, Sawynok J and Sullivan MJ: Topical 2\% amitriptyline and $1 \%$ ketamine in neuropathic pain syndromes: A randomized, double-blind, placebo-controlled trial. Anesthesiology 103: 140-146, 2005.

97. Hocking $\mathrm{G}$ and Cousins MJ: Ketamine in chronic pain management: An evidence-based review. Anesth Analg 97: 1730-1739, 2003.
98. Niesters M, Martini C and Dahan A: Ketamine for chronic pain Risks and benefits. Br J Clin Pharmacol 77: 357-367, 2014.

99. Mion G and Villevieille T: Ketamine pharmacology: An update (pharmacodynamics and molecular aspects, recent findings) Cns Neurosci Ther 19: 370-380, 2013.

100. Mahoney JM, Vardaxis V, Moore JL, Hall AM, Haffner KE and Peterson MC: Topical ketamine cream in the treatment of painful diabetic neuropathy: A randomized, placebo-controlled, double-blind initial study. J Am Podiatr Med Assoc 102: 178-183, 2012.

101. Lynch ME, Clark AJ and Sawynok J: A pilot study examining topical amitriptyline, ketamine, and a combination of both in the treatment of neuropathic pain. Clin J Pain 19: 323-328, 2003.

102. Lynch ME, Clark AJ, Sawynok J and Sullivan MJ: Topical amitriptyline and ketamine in neuropathic pain syndromes: An open-label study. J Pain 6: 644-649, 2005.

103. Somberg JC and Molnar J: Retrospective study on the analgesic activity of a topical (TT-CTAC) cream in patients with diabetic neuropathy and other chronic pain conditions. Am J Ther 22: 214-221, 2015.

104. Javed S, Petropoulos IN, Alam U and Malik RA: Treatment of painful diabetic neuropathy. Ther Adv Chronic Dis 6: 15-28, 2015.

105. Stanos SP and Galluzzi KE: Topical therapies in the management of chronic pain. Postgrad Med 125 (4 Suppl): S25-S33, 2013.

106. Barkin RL: The pharmacology of topical analgesics. Postgrad Med 125 (4 Suppl 1): S7-S18, 2013.

107. Pickering G, Martin E, Tiberghien F, Delorme C and Mick G: Localized neuropathic pain: An expert consensus on local treatments. Drug Des Devel Ther 11: 2709-2718, 2017.

This work is licensed under a Creative Commons Attribution-NonCommercial-NoDerivatives 4.0 International (CC BY-NC-ND 4.0) License. 